Article

\title{
Hydrothermal-Microwave Processing for Starch Extraction from Mexican Avocado Seeds: Operational Conditions and Characterization
}

\author{
Rafael G. Araújo ${ }^{1,2}$, Rosa M. Rodríguez-Jasso ${ }^{2}$, Héctor A. Ruiz ${ }^{2}{ }^{\circ}$, Mayela Govea-Salas ${ }^{3}$, \\ Walfred Rosas-Flores ${ }^{4}{ }^{\circ}$, Miguel Angel Aguilar-González ${ }^{5}{ }^{\circledR}$, Manuela E. Pintado ${ }^{6}$, \\ Claudia Lopez-Badillo ${ }^{1}$, Cynthia Luevanos ${ }^{1}$ and Cristobal Noe Aguilar ${ }^{1, *}$ (i) \\ 1 Bioprocesses \& Bioproducts Research Group, Food Research Department, School of Chemistry, \\ Universidad Autónoma de Coahuila, 25280 Saltillo, Mexico; rafael.araujo@uadec.edu.mx (R.G.A.); \\ cllopezb@uadec.edu.mx (C.L.-B.); cluevano@uadec.edu.mx (C.L.) \\ 2 Biorefinery Group, Food Research Department, School of Chemistry, Universidad Autónoma de Coahuila, \\ 25280 Saltillo, Mexico; rrodriguezjasso@uadec.edu.mx (R.M.R.-J.); hector_ruiz_leza@uadec.edu.mx (H.A.R.) \\ 3 Nanobioscience Group, Food Research Department, School of Chemistry, Universidad Autónoma de \\ Coahuila, 25280 Saltillo, Mexico; m.govea.salas@uadec.edu.mx \\ 4 Department of Chemical and Biochemical Engineering, National Technological Institute of Mexico/I.T. \\ Durango, Felipe Pescador 1830, Nueva Vizcaya, 34080 Durango, Mexico; wrosas@itdurango.edu.mx \\ 5 Center for Research and Advanced Studies of the National Polytechnic Institute, CINVESTAV-Saltillo, \\ Avenida Industria Metalurgia 1062, Parque Industrial Saltillo-Ramos Arizpe, 25900 Ramos Arizpe, Mexico; \\ miguel.aguilar@cinvestav.edu.mx \\ 6 Center for Biotechnology and Fine Chemistry, School of Biotechnology, Portuguese Catholic University, \\ 4202-401 Porto, Portugal; mpintado@porto.ucp.pt \\ * Correspondence: cristobal.aguilar@uadec.edu.mx; Tel.: +52-84-4416-9213
}

Received: 14 May 2020; Accepted: 25 June 2020; Published: 29 June 2020

\begin{abstract}
Avocado seeds are an agroindustrial residue widely produced in Mexico that are causing various environmental problems due to their accumulation. The evaluation of avocado residues to recover biopolymers by microwave-assisted extraction (MAE) and the characterization of avocado starch properties were studied in the present work. A central-composite design was used to optimize the MAE process. Moreover, a comparison was performed between MAE non-isothermal mode (NO-ISO) and conventional extraction. Starch optimization by MAE was obtained at $161.09^{\circ} \mathrm{C}$ for 56.23 min with an extraction yield of $49.52 \% \pm 0.69 \%$, while with NO-ISO at $161{ }^{\circ} \mathrm{C}$ was obtained $45.75 \% \pm 2.18 \%$. Conventional extraction was $39.04 \% \pm 2.22 \%$. Compared with conventional starch, MAE starch showed similar proprieties and molecular spectra. In contrast, MAE starch showed high solubility, low water absorption capacity, a non-granular structure with small particle size $(<2 \mu \mathrm{m})$ and polydispersity of fragments at different sizes of polymers. Therefore, MAE is a viable technology to extract the starch, and avocado seed can be considered an excellent starch source for the development of novel functional foods, contributing to promoting sustainability across the food chain.
\end{abstract}

Keywords: avocado seeds; microwave-assisted extraction; starch source

\section{Introduction}

Avocado (Persea americana Mill) is a native fruit of Mexico and Central America that is nowadays consumed worldwide due to its very complete nutritional content and many positive health benefits [1,2]. In 2018, avocado production in Mexico was more than two million tons, valued at more than five billion dollars, and representing more than $34 \%$ of worldwide production [3,4]. 
The avocado seed represents approximately $13-17 \%$ of the fruit. It is composed of many bioactive compounds, sugars, proteins and starches, which are the main compound of approximately $60 \%$ by dry weight [5-7]. However, avocado waste-like many fruit wastes-is a growing concern worldwide, as it represents an environmental, social and economic problems [8]. For the modern sustainable food industry, waste generated is one of the main concerns. Therefore, the recovery of fruit waste offers the possibility of obtaining ingredients with new nutritional and functional properties. Its management is also a crucial issue for the modern avocado industry.

Starch is a natural biopolymer and the main reserve of carbohydrates in plants as a form of glucose [9]. Starch is an important sustainable resource for various industries that can be obtained easily from fruits, seeds and tubers. The most common sources of commercial starch are cereals such as corn and wheat as well as the roots or tuberous of cassava and potato $[9,10]$. Tuberous plants have about $16-24 \%$ of starch in weight; the rest is water and traces of lipids and proteins. In contrast, the content of starch in cereals can be more than $60 \%$ and $10-20 \%$ of fibers, proteins and lipids, which is an important factor to take into consideration for manufacturing processes and further transformations $[10,11]$. Starch is an abundant, available, renewable, versatile and biodegradable polymer composed mainly of amylose, amylopectin and some minor components as protein, lipids and minerals that can be extracted with high purity [12,13]. Amylose is a linear polymer of $\alpha-1,4$-linked glucans. Amylopectin is a larger molecule with highly $\alpha-1,6$ branched chains [10,14-16]. Normaly, starches contain $75-80 \%$ amylopectin and 20-25\% amylose, with some exceptions such as modified some starch that contains only amylopectin. The morphology, structure, size and relationship of amylose and amylopectin starch granules are variable depending on botanical source, stage of plant development and environmental conditions. These make starch granules a complex polysaccharide and variable [15]. Starch is a polymer with structural and physical properties that promote high demand, which is reflected in a growing market in recent years [17]. Thickening, gelling, stabilizing and binding properties make starch a widely used ingredient in food, cosmetic, pharmaceutical, textile, study, biodegradable materials and other industrial products. $[15,16,18,19]$. Currently, there is a great need to find new sources of starch that are natural and economically viable to use and reduce common sources and decrease the use of essential foods [20].

Some authors have reported works on the extraction and characterization of starch from avocado seeds, but using only by conventional extraction, such as crushing the seed with the addition of some salts such as sodium bisulfite, followed by several washes and filtrations to recover the starch, and a starch extraction yield about $20 \%$ dry weight $[9,15,20]$. Hydrothermal processing such as microwave-assisted extraction (MAE) is considered a green and safe technology to extract value-added compounds such as polyphenols and polymers such as pectin or starch due to its ease of use and the possibility of using only water as extraction solvent [21,22]. The microwave extraction mechanism is based on heating induced by microwave radiation, which creates a dipole moment caused by the agitation of water molecules within the extraction material, which sometimes causes pores or breakage of plant material and consequently a greater release of compounds [23,24]. This type of extraction is considered a technology with several advantages, such as short extraction times, higher extraction performance and less solvent consumption. For this reason, MAE technology is used on an industrial scale to obtain bioactive compounds-mainly polymers, antioxidants and oils rich in carotenoids or extracts of polyphenols-from plants and residues. Sometimes it is combined with other techniques such as ultrasound and pulsed electric field—or with some modifications to the equipment such as continuous MAE [24,25].

The objective of the present study was to evaluate and optimize the MAE conditions of avocado seed starch and characterize and promote an unconventional and viable source of starch for introduction in different industrial applications. 


\section{Materials and Methods}

\subsection{Raw Material}

Avocado seeds were obtained from Hass variety in a ready-to-eat ripening stage from a local restaurant in Saltillo, Coahuila, Mexico. The seeds were washed to remove pulp residues and cut into small pieces with a kitchen knife for further freeze-drying (Labconco Freezone 4.5, Kansas City, MO, USA) [26]. Lyophilization was used to be able to create a homogeneous batch of avocado seed to find the optimal conditions of extraction, which was not achieved using fresh seed since great variability was obtained in the same treatments, derived from variations of starch content between seeds. on the other hand, the convection drying method decreased the starch extraction yield perhaps because the heating caused Maillard reactions on the surface of the seed pieces which created a caramel-like layer. Once lyophilized, the seeds were ground using a blender (Osterizer ${ }^{\circledR}, 10$ velocities) for $5-10 \mathrm{~s}$ and sieved with mesh numbers 18 and 35 to obtain a particle size between $0.3-1 \mathrm{~mm}$. The flours were stored at room temperature protected from light and air. The determination of the proximal composition of the avocado peel was determined by the standards of official methods of analysis (AOAC 1990) [27] to lipids, protein and ashes, 932.06, 925.09, 923.03 methods, respectively and 991.43 for insoluble and soluble fiber.

\subsection{Avocado Starch Extraction by MAE}

The starch was extracted by MAE (CEM Mars 6, USA) with temperature control in Teflon vessels of $70 \mathrm{~mL}$ (Xpress). The extraction was performed with a relationship of 1:20 (w/v), $20 \mathrm{~mL}$ of water with $1 \mathrm{~g}$ of the dry avocado seed, $2.45 \mathrm{GHz}$ and $1200 \mathrm{~W}$ [28]. Each treatment was performed by triplicate. After extraction, the liquid phase was recovered by filtration and then the starch was precipitated with ethanol with a relationship 1:2 (v/v), after $12 \mathrm{~h}$ of precipitation, the starch was recovery by decantation and centrifugation at $4000 \times g$ by $10 \mathrm{~min}$ (Hermle Z326 K, Wehingen, Germany) and finally freeze-dried [29]. The starch yield was calculated by the following Equation (1):

$$
\text { Yield }(\%)=\frac{\text { mass of dry starch recovered }}{\text { mass of dry avocado seed }} \times 100 \%
$$

Optimization of Starch Extraction

A central composite design (CCD) with a 99\% confidence level was used to obtain optimal conditions for the highest starch extraction yield. For the optimization of starch extraction yield from avocado seeds, a response surface methodology was applied. Table 1 shows the independent variables of temperature $\left(\mathrm{X} 1,{ }^{\circ} \mathrm{C}\right)$ and time $(\mathrm{X} 2, \mathrm{~min})$ for three variation levels on starch extraction yield (\%), obtained of a CCD with two factors and 3 replicates of the center point leading. Low and high factors were coded as -1 and +1 ; the center point was coded as 0 . The data were analyzed by statistical software STATISTICA $7^{\circledR}$ to obtain the optimal condition (OC) and later validated by extraction with the conditions estimated by the software. The validation was performed by triplicate. The results were analyzed by analysis of variance (ANOVA), and the responses and variables (in coded unit) were correlated by response surface analysis to obtain the coefficients of Equation (2):

$$
Y=\beta_{0}+\sum_{i=1}^{n} \beta_{i} X_{i}+\sum_{i=1}^{n} \beta_{i i} X_{i}^{2}+\sum_{i=1}^{n-1} \sum_{j=i+1}^{n} \beta_{i j} X_{i} X_{j}
$$

In Equation (2), $Y$ represents the response or dependent variable (starch yield extraction); $\beta_{0}$ is the interception coefficient; $\beta_{i}, \beta_{i i}$ and $\beta_{i j}$ are the coefficients estimated by the model and $X_{i}$ and $X_{j}$ are the coded levels of the independent variables (temperature and time). 
Table 1. Experimental conditions used for starch extraction from avocado seed according to central composite design with two variables, temperature $\left(\mathrm{X}_{1}\right)$ and time $\left(\mathrm{X}_{2}\right)$ and results obtained for the response starch extraction yield $(\%(w / w))$.

\begin{tabular}{cccccc}
\hline \multirow{2}{*}{ Assay } & \multicolumn{4}{c}{ Variables } & \multirow{2}{*}{$\begin{array}{c}\text { Starch Yield } \\
(\%(w / w))\end{array}$} \\
\cline { 2 - 5 } & \multicolumn{2}{c}{$\mathbf{X}_{\mathbf{1}}$} & \multicolumn{2}{c}{$\mathbf{X}_{\mathbf{2}}$} & \\
\hline 1 & 90 & $(-1)$ & 30 & $(-1)$ & $26.13 \pm 0.87$ \\
2 & 90 & $(-1)$ & 60 & $(1)$ & $27.48 \pm 1.87$ \\
3 & 90 & $(-1)$ & 45 & $(0)$ & $27.36 \pm 4.92$ \\
4 & 180 & $(1)$ & 30 & $(-1)$ & $47.31 \pm 0.85$ \\
5 & 180 & $(1)$ & 60 & $(1)$ & $44.82 \pm 1.00$ \\
6 & 180 & $(1)$ & 45 & $(0)$ & $46.06 \pm 0.81$ \\
7 & 135 & $(0)$ & 30 & $(-1)$ & $43.75 \pm 0.28$ \\
8 & 135 & $(0)$ & 60 & $(1)$ & $45.48 \pm 0.26$ \\
9 & 135 & $(0)$ & 45 & $(0)$ & $42.97 \pm 0.53$ \\
10 & 135 & $(0)$ & 45 & $(0)$ & $44.15 \pm 1.46$ \\
11 & 135 & $(0)$ & 45 & $(0)$ & $43.88 \pm 3.83$ \\
\hline
\end{tabular}

The OC was extracted and validated in non-isothermal (NO-ISO) mode to decrease the energy expenditure of isothermal extraction and compare if significant differences are found.

\subsection{Avocado Starch Extraction by a Conventional Method (CONV)}

At present, the conventional process of starch extraction includes crushing of the vegetal material using water in a solution of salts as sodium metabisulfite or sodium bisulfite at $0.1-0.2 \%$ $(w / v)[15,18,30-32]$, sodium hydroxide solutions $0.05-0.1 \%(w / v)[33,34]$ or extractions with enzymatic catalysts (xylanase protease) [35]. To extract starch from the avocado seed was followed the methodology described by Chel-Guerrero et al. [15], with some modifications. Seed powder was mixed with a sodium bisulfite solution (1500 ppm) at 1:5 (w/v) and was powdered in a blender (Oster) for $30 \mathrm{~s} \mathrm{twice.}$ The mash was filtered through a sieve of fine muslin cloth of $150 \mathrm{~mm}$ mesh size to obtain the starch in a liquid fraction and separate the fibers. The recovered starch was washed three times with distilled water and then centrifuged at 2200× $g$ for $10 \mathrm{~min}$ (Hermle Z326K, Wehingen, Germany). The starch was dried at $40{ }^{\circ} \mathrm{C}$ for $12 \mathrm{~h}$ in a convection oven. The starch yield was calculated by Equation (1). The resulting starch was powder and stored at room temperature in a sealed flask.

\subsection{Starch Characterization}

Starch characterization was performed to identify MAE modifications in avocado starch with OC and OC NO-ISO and compare with the starch obtained by conventional extraction.

\subsubsection{Water Absorption and Solubility of Starch}

Solubility, swelling power and water absorption patterns were measured at $60,70,80$ and $90{ }^{\circ} \mathrm{C}$ following Chel-Guerrero et al. [15] with some modifications. Briefly, $20 \mathrm{~mL}$ of a $1 \%$ starch suspension $(w / v)$ was prepared in a previously tared $50 \mathrm{~mL}$ centrifuge tube. The tubes were kept at a constant temperature $\left(60,70,80\right.$ and $\left.90^{\circ} \mathrm{C}\right)$ in a water bath for $30 \mathrm{~min}$ with manual agitation at each $5 \mathrm{~min}$. The suspension was then centrifuged at $2120 \times g$ for $15 \mathrm{~min}$, the supernatant decanted and the swollen granules weighed. Water absorption capacity was measured using the same samples but was expressed as the weight of the gel formed per sample, divided by sample weight. Solubility and swelling power were calculated using the following Equations (3) and (4):

$$
\text { Solubility }(\%)=\frac{d r y \text { weight at } 120^{\circ} \mathrm{C}}{\text { weigth of sample }(\mathrm{g})} \times 400 \%
$$




$$
\text { Swelling power }=\frac{\text { weight of swollen granules }(\mathrm{g})}{\text { sample weight }(\mathrm{g}) \times(100-\% \text { solubility })}
$$

\subsubsection{Scanning Electron Microscopy (SEM)}

SEM analysis was performed in a scanning electron microscope Philips XL30, ESEM (environmental scanning electron microscope) with a GSED (gaseous secondary electrons detector) [36]. The samples were mounted in a metallic bracket and a gold/palladium coating was applied to provide conductivity. The micrographs were obtained with an accelerating potential of $30 \mathrm{kV}$ under a low vacuum. Magnification of 750 and 7500 were selected for the study.

\subsubsection{Fourier-Transform Infrared Spectroscopy (FTIR)}

The FTIR spectra of the samples were recorded on the spectrophotometer PerkinElmer Frontier with attenuated total reflectance (ATR). The analysis was conducted from 4000 to $600 \mathrm{~cm}^{-1}$ with a resolution of $4 \mathrm{~cm}^{-1}$ and 16 scans [37].

\subsubsection{Thermogravimetric Analysis (TGA)}

The TGA spectra of the samples were recorded PerkinElmer TGA 4000 thermogravimetric analyzer. The samples $\left(4-5 \mathrm{mg}\right.$ ) were heated from 30 to $600{ }^{\circ} \mathrm{C}$ at $20^{\circ} \mathrm{C} / \mathrm{min}$ with a nitrogen gas flow of $20 \mathrm{~mL} / \mathrm{min}$ [38].

\subsubsection{Differential Scanning Calorimetry (DSC)}

The thermal characteristics of avocado starch were determined as follows: Gelatinization onset $\left(T_{0}\right)$, peak $\left(T_{p}\right)$, conclusion $\left(T_{c}\right)$ temperatures and melting enthalpies per gram of dry starch $(\Delta H)$ were measured in excess water $(1: 3$ starch dry matter $(\mathrm{dm})$ : water) using differential scanning calorimeter (DSC) (Q2000, TA Instruments, New Castle, DE, USA) and results were analyzed with TA Universal analysis software ${ }^{\odot}$. Samples were heated from 25 to $250{ }^{\circ} \mathrm{C}$ at $5{ }^{\circ} \mathrm{C} / \mathrm{min}$. An empty pan was used as a reference. Calibration was performed with indium.

\subsubsection{Wide-Angle X-Ray Scattering}

The diffractogram was performed with powder starch containing $10 \%$ of moisture, an interval of $2 \theta$ angles ranged from $7^{\circ}$ to $50^{\circ}$ in the X-ray diffractometer (Panalytical Empyrean, Netherlands), at a rate of $4.3^{\circ} / \mathrm{min}$ operating at a power of $40 \mathrm{kv} / 30 \mathrm{~mA}$ [39]. The crystallinity degree was calculated by the following Equation (5):

$$
C d=\frac{A c}{A c+A a} \times 100 \%
$$

where $C d$ means the relative grade of crystallinity; $A C$ means the crystallinity area of $\mathrm{X}$-ray diffractogram and $A a$ means to an amorphous area of X-ray diffractogram.

\subsubsection{Molecular Exclusion Chromatography}

Starch molecular weight distribution profiles were determined by using a double gel permeation chromatography (GPC) column, PL Aquagel-OH MIXED-H $8 \mu \mathrm{m}, 300 \times 7.5 \mathrm{~mm}$ (Agilent Technologies, Stockport, UK) in HPLC Agilent Technologies 1260 Infinity II with a refractive index detector, adapted from Nie et al. [40]. An aqueous solution of starch $0.5 \%(w / v)$ was prepared and mechanically stirred for $1 \mathrm{~h}$ at room temperature. Two milliliters of solution were filtered with a $0.45 \mu \mathrm{m}$ filter, to inject $50 \mu \mathrm{L}$ in the column at $40^{\circ} \mathrm{C}$ using deionized water as eluent at a flow rate of $1 \mathrm{~mL} / \mathrm{min}$. Aqueous SEC startup kit of Polyethylene oxide/glycol (Agilent Technologies) was used as a calibration curve. 


\subsection{Statistical Analyses}

Statistical analyses were performed to calculate the average tendency and deviation. To compare the yields of starch extraction from avocado seed and optimize the conditions of extraction analysis of variance (ANOVA) and Tukey's test with a 99\% confidence level were run in the STATISTICA $7^{\circledR}$ software (StatSoft, Inc., Tulsa, OK, USA).

\section{Results and Discussion}

\subsection{Microwave-Assisted Extraction of Avocado Starch}

The dry avocado seed used contains $6.20 \pm 0.01 \%$ of moisture, $3.63 \pm 0.04 \%$ of lipids, $3.06 \pm 0.15 \%$ of proteins, $20.65 \pm 0.03 \%$ of insoluble fiber and $64.61 \pm 4.79 \%$ of soluble fiber. Starch extraction from avocado seed was very effective using MAE technology coupled to the process of obtaining by hot filtration and ethanol precipitation, generating yields of $47 \%(w / w)$. Table 1 shows the values of starch extraction yields of each treatment. The degree of solubilization/extraction of starch increased for higher heating temperatures, ranged between $42.97 \%$ and $47.31 \%$ at 135 and $180{ }^{\circ} \mathrm{C}$ and decreasing of $47.31 \%$ to $44.82 \%$ at $180{ }^{\circ} \mathrm{C}$ with the increasing the extraction time and decrease to $26-27 \%$ at the conditions of less temperature $\left(90^{\circ} \mathrm{C}\right)$. Chel-Guerrero et al. [15] showed a yield of $20 \%$ in wet basis from Hass avocado using a conventional extraction with saline solutions, that means a lower yield of extraction than the yield obtained by MAE, considering that the seed has about $50 \%$ of moisture, in wet basis the yield of MAE will be about $25 \%$, which is a superior yield.

\subsection{Statistical Analysis and Optimization of Starch Extraction}

Table 1 shows the experimental data of the treatments of the experimental design. The analysis of variance (ANOVA) was carried out to obtain, $F$-value, $p$-value and lack of fit of the model and the independent variables, temperature and time, $X_{1}$ and $X_{2}$, respectively. The ANOVA results showed in Table 2, revealed that the second-order polynomial model was found to be for prediction of starch extraction yield response within the range of experimental variables. The determination coefficient of the model was $\mathrm{R}^{2}=0.9949$, indicating a high adjustment of the model and only $0.51 \%$ of the total variation was not explained by the proposed model. The current model showed no significant lack of fit, which means a good adjustment of the model.

Table 2. Analysis of variance (ANOVA) for optimization of the yield of starch extraction from avocado seeds, model as a function of temperature $\left(X_{1}\right)$ and time $\left(X_{2}\right)$.

\begin{tabular}{cccccc}
\hline Source & Sum of Squares & df & Mean Square & F-Value & $p$-Value \\
\hline Model & 703.87 & 5 & 140.77 & 196.75 & $0.0001^{*}$ \\
$\mathrm{x}_{1}$ & 545.41 & 1 & 545.41 & 759.45 & $0.000001^{*}$ \\
$\mathrm{x}_{1}{ }^{2}$ & 146.39 & 1 & 146.39 & 203.83 & $0.000033^{*}$ \\
$\mathrm{x}_{2}$ & 0.06 & 1 & 0.06 & 0.08 & 0.78802 \\
$\mathrm{x}_{2}{ }^{2}$ & 0.24 & 1 & 0.24 & 0.33 & 0.58952 \\
$\mathrm{x}_{1} \mathrm{x}_{2}$ & 3.69 & 1 & 3.69 & 5.15 & 0.07259 \\
Residual & 3.59 & 5 & 0.72 & & \\
Lack of fit & 2.81 & 3 & 0.94 & 2.45 & 0.3027 \\
Pure error & 0.76 & 2 & 0.38 & & \\
Cor total & 707.2153 & 10 & & & \\
$\mathrm{R}^{2}$ & 0.9949 & & & & \\
Adj $\mathrm{R}^{2}$ & 0.9899 & & & \\
C.V. & 2.12 & &
\end{tabular}


It was found that the response of temperature was significant $(p$-value $<0.01)$ with a linear and quadratic effect, which shows that the temperature is the factor with effect to extract/solubilize the starch from an avocado seed. The high effect of temperature in the extraction of starch can be explained by the effect of high temperature on gelation of the starch $\left(>90^{\circ} \mathrm{C}\right)$, which increases the solubility of the starch in water, therefore thus increases the yields of extraction. This effect is observable in Table 2 since at a low temperature $\left(90^{\circ} \mathrm{C}\right)$ the yield of starch extraction is lower compared with that obtained at higher temperatures $\left(135\right.$ and $\left.180^{\circ} \mathrm{C}\right)$. The yield of extraction between 90 and 135 or $180^{\circ} \mathrm{C}$ increases 1.8 times.

The time did not have a significant effect on the model, but it was evident at a temperature of $180{ }^{\circ} \mathrm{C}$ that with increasing time of extraction from 30 to $60 \mathrm{~min}$, the yield of starch extraction decreases, which indicates that at this temperature the starch is degrading maybe into oligosaccharides, glucose or other degradation compounds derived from the effect of self-hydrolysis caused by the high temperature.

The second-order polynomial model of the optimization of starch extraction yield (SEY) as a function of the factor with statistical significance, temperature $\left(X_{1}\right)$, is expressed in the next Equation (6):

$$
\mathrm{Y}(\%)=43.92+9.54 \mathrm{X}_{1}-7.60 \mathrm{X}_{1}^{2}
$$

The second-order polynomial of Equation (1) was plotted a three-dimensional response surface to obtain the optimum condition to starch extraction from avocado seed (Figure 1). The starch extraction yield was estimated to be $46.72 \%$ at optimum condition (temperature: $161.09{ }^{\circ} \mathrm{C}$, time: $56.23 \mathrm{~min}$ ). With the validation of optimum condition, performed by triplicate, a yield of starch extraction of $49.52 \pm 0.69 \%$ was obtained, showing that the model has a good fit for avocado starch extraction.

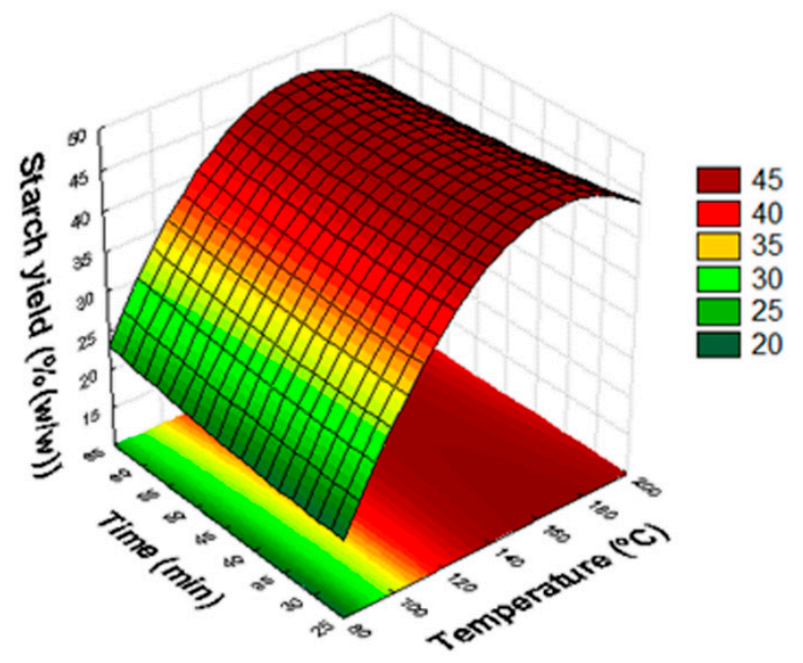

Figure 1. Response surface and contour plot showing the optimization of starch extraction by effects of temperature $\left(X_{1}\right)$ and time $\left(X_{2}\right)$.

\subsection{Avocado Starch Extraction MAE NO-ISO and Conventional Extraction}

By comparing the starch extraction yields of the three methodologies tested, MAE obtained the best yields. The yield of starch extraction by OC NO-ISO was slightly lower (45.75\%), when compared to the extraction with OC (49.52\%) but was not statistically different when compared by the Tukey's test with $99 \%$ confidence level. With the conventional extraction, the yield of starch extraction was lower $(39.04 \%)$ and statistically different from the methods of extraction by MAE, indicating the high efficiency of the extraction promoted by microwave radiation. To select the condition of starch extraction by MAE (OC or OC NO-ISO) is necessary for an economic study to evaluate the energetic costs with the benefits of obtaining more starch or less starch with a low energetic cost. As MAE treatments have no statistical difference in extraction yields can be cost-effectively using OC NO-ISO 
condition because the low extraction time, only heating time (about $12 \mathrm{~min}$ ), allows more extractions and more starch extraction, when compared with $\mathrm{OC}$ in the same time of extraction.

\subsection{Starch Characterization}

\subsubsection{Scanning Electron Microscopy (SEM)}

Figure 2 shows the scanning electron micrographs recorded for avocado seed flour (A), the avocado starch extracted by MAE with OC and OC NO-ISO (B and C) and by conventional extraction (D) and corresponding fiber residues (1). The size reported to the starch granules of the avocado seed is between $5-35 \mu \mathrm{m}[15,18]$. Starch can be classified into four categories by the size: large $(>25 \mu \mathrm{m})$, medium $(10-25 \mu \mathrm{m})$, small $(5-10 \mu \mathrm{m})$ and very small $(<5 \mu \mathrm{m})[20,41]$.

Native starch granules of avocado seed flour and the starch obtained by the conventional method shown in Figure 2A,D, respectively, are within this size range $(5-25 \mu \mathrm{m})$ with a clear, regular elliptical shape with smooth surfaces and classified as medium and small granules. The starch obtained by MAE have not regular shape and the same size, showing a degraded structure in an agglomerated form. With OC the starch obtained shows a pressing shape as in the same way if it sees the resulting fiber residues while the starch obtained by OC NO-ISO shows very small oval shape $(<0.5 \mathrm{~mm})$ and in fiber, residues is possible to see the wells where the starch granules were and some residue of starch. The effect of degradation of the starch structure by microwave radiation has also been demonstrated by Fan et al. [42] showing that starch granules lost their birefringence and the granules ruptured completely at $80^{\circ} \mathrm{C}$. A similar effect was reported by Xie et al. [43] showing that treatment for $20 \mathrm{~s}$ with final temperatures of $95^{\circ} \mathrm{C}$ caused serious deformation, fracture, and collapse of most starch granules. Analyzing Figure 2D1, it is possible to see starch granules after extraction with the fiber residues explaining the low extraction yield of conventional extraction and demonstrating the efficiency of starch extraction of MAE.

\subsubsection{Solubility, Swelling Power (SP) and Water Absorption Capacity (WAC) of Starch}

Avocado starch patterns of solubility, swelling power (SP) and water absorption capacity (WAC) are shown in Figure 3. Solubility, SP and WAC are directly correlated with increases in temperature. The continuous rising of starch swelling, as the effect of the increase in temperature, is caused by the rupture of intermolecular bridges (hydrogen bond cleavage) in amorphous zones and allows a progressive and irreversible water absorption. The molecular organization of starch granules is irreversibly destroyed with gelatinization and increases the starch solubility due to the hydrogen bond cleavage and water fixation $[13,15]$.

The CONV starch shows a normal behavior with temperature increases $\left(60-90^{\circ} \mathrm{C}\right)$ showing an increase of solubility of 12.8 to $24.3 \%$, WAC of 6.7 to $13.2 \mathrm{~g} / \mathrm{g}$ and SP of 7.7 to $17.4 \mathrm{~g} / \mathrm{g}$. Similar results were presented by dos Santos et al. [12], Chel-Guerreo [15] and Silva et al. [26] with avocado seed starch obtained by conventional methods. Contrary to the MAE starches have completely different behavior when compared with CONV starch and other authors. The MAE starches have a high solubility and increase with the temperature of 60 to $90{ }^{\circ} \mathrm{C}$, the solubility increases of $86.3 \%$ and $93.2 \%$ to $93.6 \%$ and $96.8 \%$, in OC and OC NO-ISO starches, respectively. Consequently, the starches have a low WAC, between $1-2 \%$, decreasing with the increase in temperature as a consequence of the increase of solubility. The high SP of MAE starches, which had no significant fluctuation with temperature, can be explained by the MAE effect in the structure of the starch. As shown in Figure 2, the MAE starch has a small size and probably these starches are small structures of amylose and amylopectin with many cleaved bonds that promote a rapid water bond and a high SP, due to the relation between a large number of water molecules by starch particle, however, the WAC is low due to the low quantity of these particles associate to the high solubility and the small particles gelatinized when compared with large size of a gelatinized granule of CONV starch. 

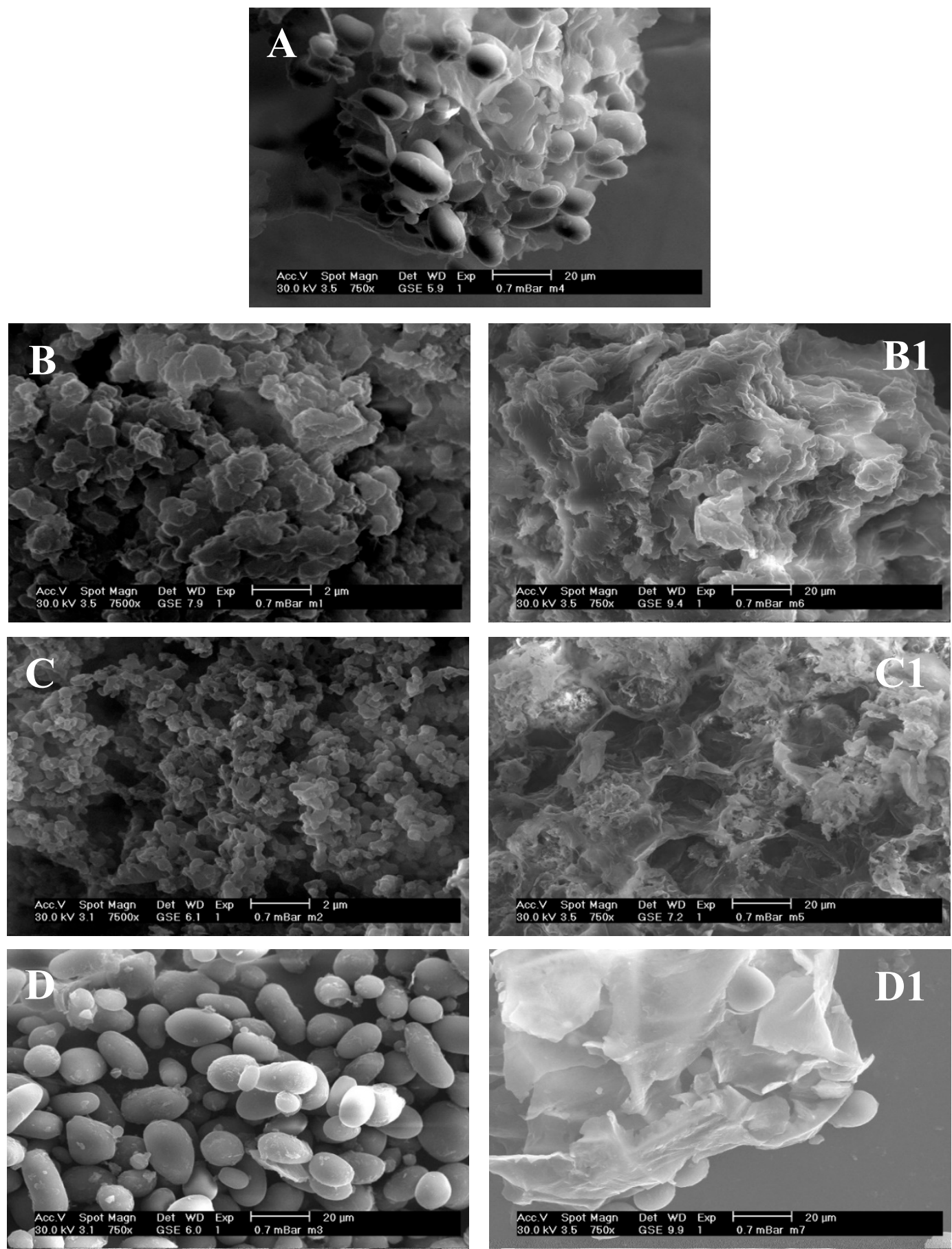

Figure 2. Scanning electron micrograph of (A) avocado seed flour, (B) avocado starch extracted by microwave-assisted extraction (MAE) with optimal condition (OC), (C) with OC MAE non-isothermal mode (NO-ISO) and (D) conventional method (CONV), and (B1,C1,D1) respective residues resulting from each extraction. 

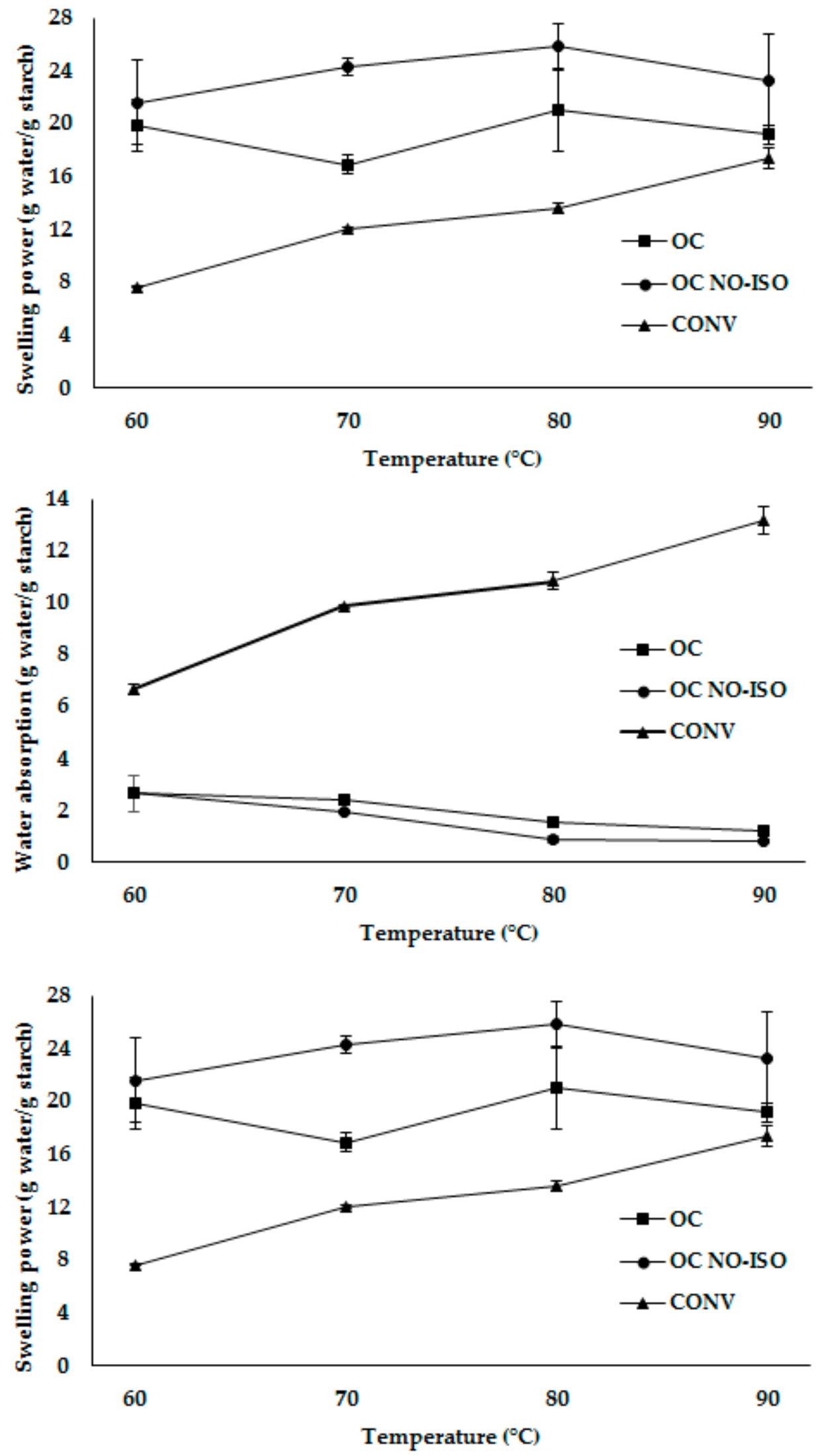

Figure 3. Solubility, water absorption and swelling power patterns of avocado starch extracted by MAE (OC and OC NO-ISO) and conventional method (CONV). 


\subsubsection{Thermogravimetric Analysis}

TGA analysis showed changes in a weight loss of the sample with temperature increase and was performed to determine the thermal stability of the starches. As shown in Table 3, it can be observed three mass loss during the heating process of starches, which is characteristic from starch $[18,44]$. The first weight loss starts about $70{ }^{\circ} \mathrm{C}$ to MAE starch and about $120^{\circ} \mathrm{C}$ to $\mathrm{CONV}$ starch was the result of starch dehydration. The difference showed between starches can be explained by the moisture of starches, that MAE starches have more moisture content and because they are not granular in shape it may allow a loss of water at lower temperatures. The second mass loss corresponds to the decomposition of organic matter. In this step occurred a great mass loss, which means that it has a great number of compounds with similar thermal properties, which is characteristic of a homopolysaccharide as the starch. The starch decomposition with temperatures exceeding $300^{\circ} \mathrm{C}$, consists of depolymerization of the starch, formation of pyrodextrins followed by the degradation of macromolecules in levoglucosan, furfural and volatile products and finally carbon residues that is the last mass loss. MAE starches start the second mass loss of about $280{ }^{\circ} \mathrm{C}$ and CONV starch at $300{ }^{\circ} \mathrm{C}$. This difference in temperature can be explained by the depolymerization of the starch generated with the extraction of microwaves, which begin to degrade faster at lower temperatures. Thermally, the starches are similar and these results were observed by other authors with starches from avocado seed and other botanical sources $[9,18,44-47]$.

Table 3. Differential scanning calorimetry values and temperature to each mass loss stages in Thermogravimetric Analysis (TGA) analysis of MAE avocado starch optimal condition (OC), optimal condition non-isothermal mode (NO-ISO) and conventional extraction (CONV).

\begin{tabular}{cccc}
\hline Parameters & OC Starch & OC NO-ISO Starch & CONV Starch \\
\hline DSC & & & \\
\hline $\mathbf{T}_{\mathbf{0}}\left({ }^{\circ} \mathbf{C}\right)$ & 36.86 & 46.62 & 35.94 \\
$\mathbf{T}_{\mathbf{m}}\left({ }^{\circ} \mathbf{C}\right)$ & 47.43 & 51.96 & 60.26 \\
$\mathbf{T}_{\mathbf{f}}\left({ }^{\circ} \mathbf{C}\right)$ & 58.35 & 63.29 & 74.33 \\
$\boldsymbol{\Delta} \mathbf{H}(\mathbf{J} / \mathbf{g})$ & 113.00 & 218.90 & 562.0 \\
\hline TGA & & & \\
\hline 1st & 70.33 & 77.96 & 115.23 \\
2nd & 280.5 & 280.4 & 299.3 \\
3rd & 348.28 & 343.08 & 355.74 \\
\hline
\end{tabular}

Gelatinization onset $\left(T_{o}\right)$, peak $\left(T_{p}\right)$, conclusion $\left(T_{c}\right)$ temperatures and melting enthalpies $(\Delta H)$.

\subsubsection{Differential Scanning Calorimetry}

Starch experiments an order-disorder phase transition called gelatinization when it is heated in excess of water. Gelatinization properties of starch, such as Onset Temperature $\left(\mathrm{T}_{\mathrm{o}}\right)$, Melting Temperature $\left(\mathrm{T}_{\mathrm{m}}\right)$, Conclusion Temperature $\left(\mathrm{T}_{\mathrm{f}}\right)$ and Enthalpy Increment $(\Delta \mathrm{H})$ were measured by Differential Scanning Calorimetry (DSC) and are presented in Table 3. All three samples showed one endothermic peak on the DSC thermograms, however, these peaks are located at different temperatures evidencing the effect of the MAE procedures on the starch granule structure. On one hand, the melting temperature determined for a starch obtained by conventional extraction was $60.26^{\circ} \mathrm{C}$, this value is like the reported by Chel-Guerrero et al. [15] for native starch.

In another hand, the starches obtained by OC and OC NO-ISO presented lower melting temperatures $\left(47.43^{\circ} \mathrm{C}\right.$ and $51.96^{\circ} \mathrm{C}$, respectively), this temperature decrement could be explained in terms of granules structure damage, as was previously mentioned in SEM studies (Figure 2), the starch obtained by MAE have not regular shape and the same size, showing a degraded structure in an agglomerated form, in this sense, we can say that starch is already retrograded. In other words, granule structure has lost and new structure stabilized trough double helices is formed, these low melting temperatures for retrograded starches was previously reported by (Vamadevan \& Bertoft, 
2018), evidencing that avocado starch probably contains amylopectin with DP $>50$ and lacks long internal chains (Type 1).

Another interesting factor, is the change registered for the transition enthalpy, as can be seen in Table 3. Starch endothermic enthalpy can be related to the loss of double-helical order rather than the crystalline register (Cooke \& Gidley, 1992), in this sense, it seems that the forces holding starch granules are greater in the starch obtained through CONV than MAE starches. This values for enthalpy, are similar to the reported for Silva et al. [26] for native avocado starch.

\subsubsection{Fourier-Transform Infrared Spectroscopy (FTIR)}

Figure 4 shows the infrared spectroscopy of the starches obtained by the different methodologies, showing a normal starch spectra profile for all samples analyzed. Starch is composed mainly of amylose and amylopectin that are polysaccharides composed of monomers of glucose and water. Starch has two characteristic regions of the spectrum, the -OH and - $\mathrm{CH}$ stretching vibration of the glucose unit, $3650-3000 \mathrm{~cm}^{-1}$ and the region of major adsorption bands or region of carbohydrate vibrations between $1200-800 \mathrm{~cm}^{-1}$, known as fingerprint region [37,47]. The band at $2926 \mathrm{~cm}^{-1}$ corresponds to $\mathrm{C}-\mathrm{H}$ stretching associated with the ring methane hydrogen atoms. The absorptions between 1638 and $1300 \mathrm{~cm}^{-1}$ were associated with $\mathrm{H}_{2} \mathrm{O}$-bending vibration. The intensities of bands at 1149,1077 and $996 \mathrm{~cm}^{-1}$ are associated with $\mathrm{C}-\mathrm{O}$ and $\mathrm{C}-\mathrm{C}$ stretching with some $\mathrm{C}-\mathrm{O}-\mathrm{H}$ contributions $[13,48]$. The spectra of the starches obtained are quite similar to some differences in the intensities of main bands identified and these differences of intensities can be explained by the differences in the degree of humidity of the samples or some modifications induce by MAE [49].

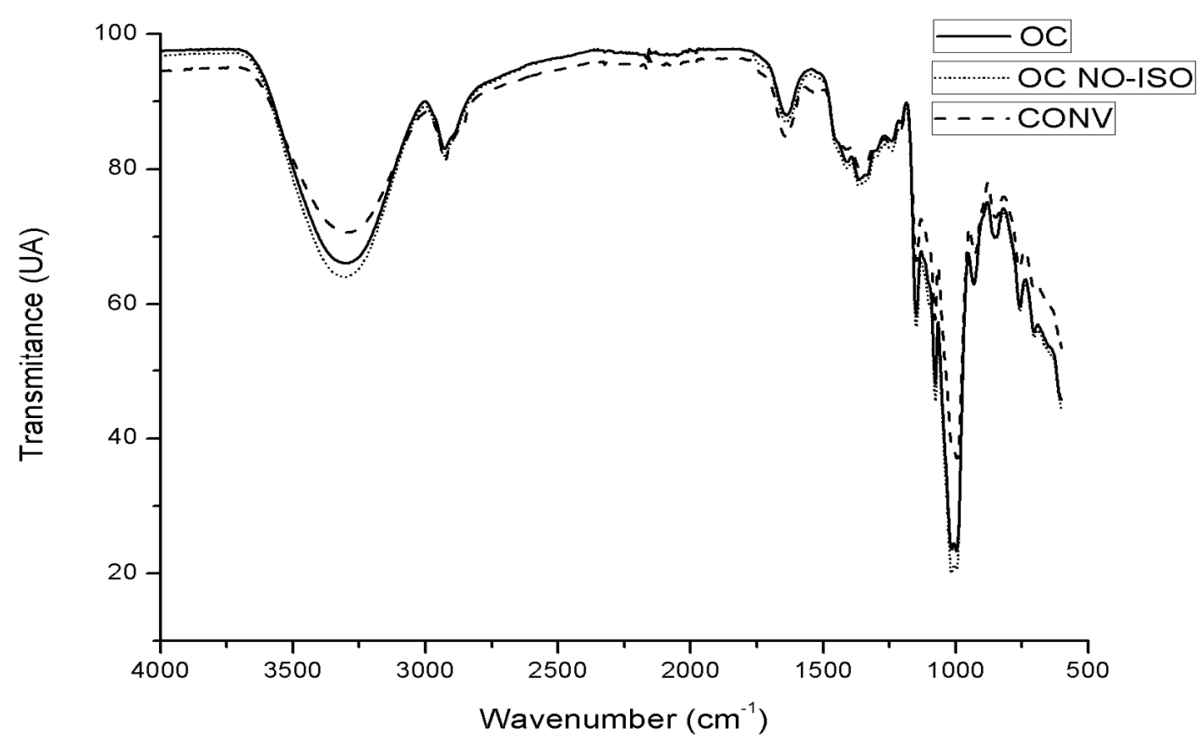

Figure 4. FTIR spectra of MAE avocado starch of optimal condition (OC), optimal condition non-isothermal mode (NO-ISO) and conventional extraction (CONV).

\subsubsection{X-Ray Diffraction (XRD)}

The X-ray diffraction patterns of the avocado starches are shown in Figure 5. The X-ray diffraction patterns of the starch obtained by MAE have the same peaks $\left(13^{\circ}\right.$ and $\left.20^{\circ} 2 \theta\right)$ and similar intensity indicating a similar crystallinity (24.15 and 25.40), though the starch extracted with CONV has a different diffraction pattern with peaks of $17^{\circ}, 20^{\circ}$ and $22^{\circ} 2 \theta$ and different crystallinity (12.19) which are similar results reported by Lacerda et al. [9]. The X-ray diffraction patterns of avocado starch indicate that the amorphous structure is more dominant than the crystalline structure. Diffraction patterns of granules starches have been classified in 3 types, A, B and C. The results obtained indicate that the starch obtained is type A because the peaks identified $17^{\circ}, 20^{\circ}$ and $22^{\circ} 2 \theta[13,50]$. MAE starches 
and CONV starch have a different pattern of diffraction indicating that they have a different structure or organization of the chains of amylose and amylopectin, creating a different level of crystallinity and changes in amorphous zone.

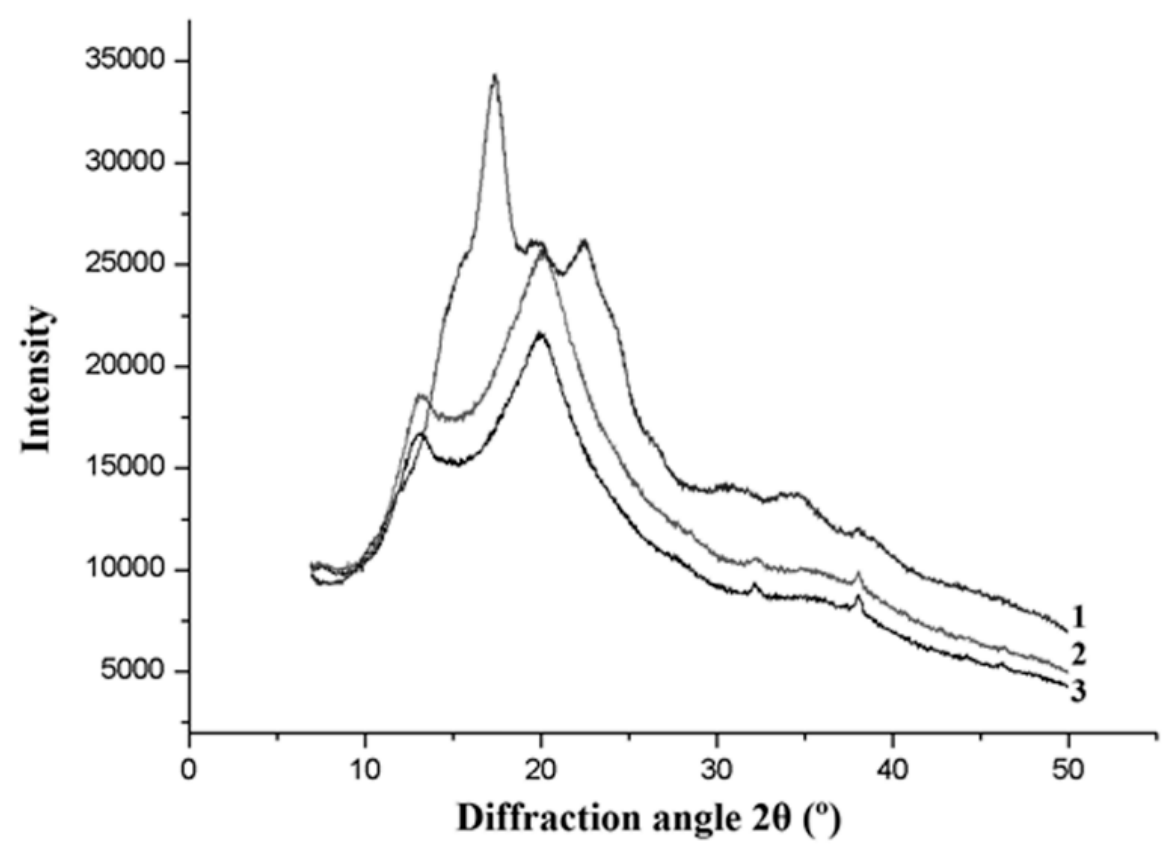

Figure 5. X-ray diffraction patterns of avocado starch extracted by the conventional method (1) and avocado starch extracted by MAE with OC NO-ISO (2) and OC (3).

\subsubsection{Molecular Exclusion Chromatography (GPC)}

Figure 6 shows the GPC chromatograms and Table 4 shows the molecular weight (MW) of main peaks identified in starches obtained by MAE and CONV. As expected, by analysis of SEM results, it was found that the starches obtained by MAE have a family of particles with different and more size groups. Starch extracted with OC has seven groups of MW between 411 and $1.91 \times 10^{8} \mathrm{~g} / \mathrm{mol}$, indicating a high fragmentation of granular structure of native starch, generating more fragments of starch that OC NO-ISO because the autohydrolysis by the effect of more time of extraction. To starch obtained with OC NO-ISO was identified five molecular weights between 533 and $1.65 \times 10^{5}$ and in CONV starch only was identified four molecular weights between 324 and $2.23 \times 10^{6}$ with low intensity indicating a low concentration of these sizes.

Table 4. Molecular weights and polydispersity of MAE avocado starch of optimal condition (OC), optimal condition non-isothermal mode (NO-ISO) and conventional extraction (CONV).

\begin{tabular}{ccccccc}
\hline & \multicolumn{2}{c}{ OC } & \multicolumn{2}{c}{ OC NO-ISO } & \multicolumn{2}{c}{ CONV } \\
\hline Peak & Mp (g/mol) & Pd & Mp (g/mol) & Pd & Mp (g/mol) & Pd \\
\hline 1 & $190,732,143^{*}$ & 1.128 & 165,387 & 1.020 & $2261,719 *$ & 1.037 \\
2 & $27,003,383^{*}$ & 1.201 & 120,484 & 1.011 & 38,172 & 1.021 \\
3 & 512,653 & 1.194 & 78,030 & 1.053 & 16,601 & 1.086 \\
4 & 262,398 & 1.036 & 3866 & 1.281 & 324 & 1.062 \\
5 & 57,883 & 1.065 & 533 & 1.155 & & \\
6 & 5165 & 1.386 & & & & \\
7 & 441 & 1.049 & & & & \\
\hline
\end{tabular}

* Value calculated by extrapolation of the calibration curve. Pd: polydispersity. 


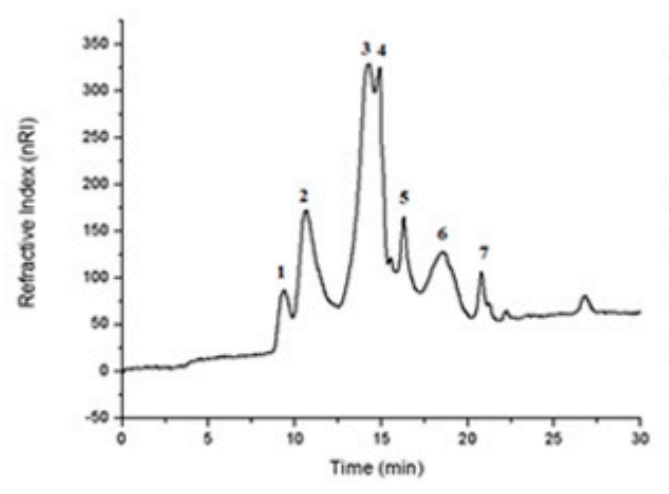

(a)

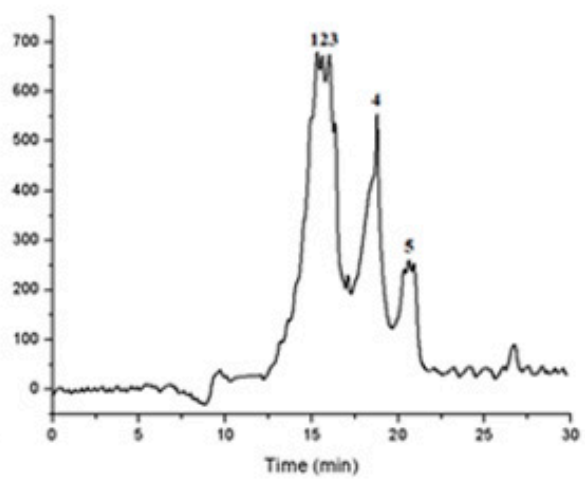

(b)

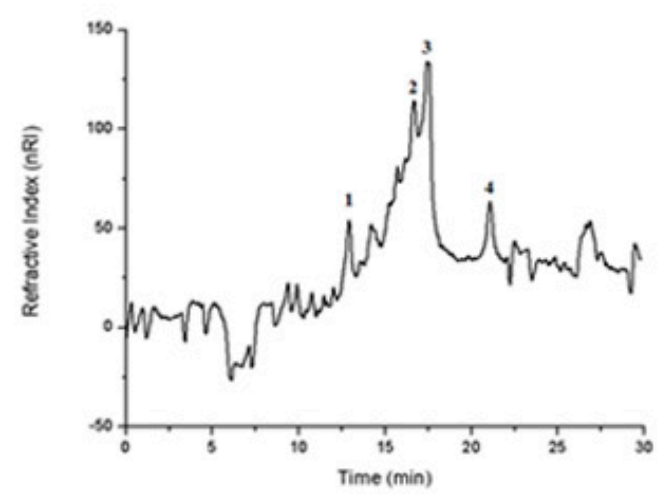

(c)

Figure 6. Double gel permeation chromatography (GPC) chromatograms of starch extracted by (a) MAE with OC, (b) with OC NO-ISO and (c) starch isolated by CONV.

Autohydrolysis is a method widely used to extract added value compounds from lignocellulosic materials as hemicellulose, lignin, oligosaccharides and others. These compounds are obtained by the deconstruction of the linkages and disruption of the cross-linked structure of lignocellulosic biomass by the effect of the autoionization of water into hydronium ions and acetyl group hydration [51-54]. A similar effect may have occurred in the structure of MAE starch by disruption of $\alpha-1-4$ and $1-6$-linked glucans of amylose and amylopectin structures.

\section{Conclusions}

Avocado seeds are a currently unused agroindustrial residue that can be utilized as an unconventional starch source. MAE technology has been shown to be a simple, efficient and rapid extraction process for the extraction of starch from avocado seeds, using only water as a solvent. However, it did induce some differences in structure and properties of starch as the solubility and water absorption capacity, the granule structure, the molecular weight of the starch and generation of chains of starch with different sizes and a structural organization that show a different diffractogram of the conventional starch. These modifications, for example, the starch chain of small size, can provide a new application to MAE starch, maybe in biotechnological applications (nanoparticle formulation, production of oligomers with bioactivity) or for example, the high starch solubility can provide good aqueous dispersion in food applications. The world of starch applications is huge and the starch modifications are so vast that they create innumerable uses. Avocado seed starch has a good potential in food industry applications as candies, meat products, drinks, sauces, bread products and many more applications as pharmaceutical products, biodegradable polymers for food packaging to decrease the use of plastics. 
Author Contributions: Conceptualization, R.G.A., R.M.R.-J., M.E.P. and C.N.A.; methodology, R.G.A.; validation, R.G.A.; formal analysis, R.G.A., M.A.A.-G., W.R.-F., C.L., C.L.-B. and W.R.-F.; investigation, R.G.A., R.M.R.-J. and H.A.R.; data curation, R.G.A. and M.G.-S.; writing-original draft preparation, R.G.A.; writing-review and editing, R.G.A., R.M.R.-J., H.A.R., W.R.-F., M.G.-S., M.E.P. and C.N.A.; visualization, R.G.A.; supervision, R.M.R.-J., M.E.P. and C.N.A.; project administration, C.N.A.; funding acquisition, R.M.R.-J., M.E.P. and C.N.A. All authors have read and agreed to the published version of the manuscript.

Funding: Authors thank the financial support given by CONACYT through the project FSSEP02-C-2018-1 A1-S-42515 and the scientific collaboration of CBQF under the FCT-Fundação para a Ciência e a Tecnologia through project UID/Multi/50016/2013.

Acknowledgments: Author Rafael G. Araújo would like to thank the National Council of Science and Technology of Mexico for the scholarship received for this project in the Ph.D. program in Food Science and Technology at the Autonomous University of Coahuila, México. Thanks to Shiva and Rohit Saxena for the technical support.

Conflicts of Interest: The authors declare no conflict of interest.

\section{References}

1. Alvarez, L.D.; Moreno, A.O.; Ochoa, F.G. Avocado. In Tropical and Subtropical Fruits: Postharvest Physiology, Processing and Packaging; Wiley-BlackWell: Hoboken, NJ, USA, 2012; pp. 437-454.

2. Cowan, A.K.; Wolstenholme, B.N. Avocado. In Encyclopedia of Food and Health; Caballero, B., Finglas, P., Toldrá, F., Eds.; Academic Press: Cambridge, MA, USA, 2016; pp. 294-300.

3. Food and Agriculture Organization of the United Nations. Agriculture Database. 2020. Available online: http://www.fao.org/faostat/en/\#data/QC (accessed on 11 February 2020).

4. SIAP. Servicio de Información Agroalimentaria y Pesquera. 2020. Available online: http://infosiap.siap.gob. mx/aagricola_siap_gb/ientidad/index.jsp (accessed on 27 February 2020).

5. Abubakar, A.N.F.; Achmadi, S.S.; Suparto, I.H. Triterpenoid of Avocado (Persea Americana) Seed and Its Cytotoxic Activity toward Breast MCF-7 and Liver HepG2 Cancer Cells. Asian Pac. J. Trop. Biomed. 2017, 7, 397-400. [CrossRef]

6. Kosińska, A.; Karamac, M.; Estrella, I.; Hernandez, T.; Bartolomé, B.; Dykes, G.A. Phenolic Compound Profiles and Antioxidant Capacity of Persea Americana Mill. Peels and Seeds of Two Varieties. J. Agric. Food Chem. 2012, 60, 4613-4619. [CrossRef] [PubMed]

7. Rodríguez-Carpena, J.G.; Morcuende, D.; Andrade, M.-J.; Kylli, P.; Estévez, M. Avocado (Persea Americana Mill.) Phenolics, in Vitro Antioxidant and Antimicrobial Activities, and Inhibition of Lipid and Protein Oxidation in Porcine Patties. J. Agric. Food Chem. 2011, 59, 5625-5635. [CrossRef] [PubMed]

8. Mirabella, N.; Castellani, V.; Sala, S. Current Options for the Valorization of Food Manufacturing Waste: A Review. J. Clean. Prod. 2014, 65, 28-41. [CrossRef]

9. Lacerda, L.G.; Colman, T.A.D.; Bauab, T.; Da Silva Carvalho Filho, M.A.; Demiate, I.M.; De Vasconcelos, E.C.; Schnitzler, E. Thermal, Structural and Rheological Properties of Starch from Avocado Seeds (Persea Americana, Miller) Modified with Standard Sodium Hypochlorite Solutions. J. Therm. Anal. Calorim. 2014, 115, 1893-1899. [CrossRef]

10. Khlestkin, V.K.; Peltek, S.E.; Kolchanov, N.A. Review of Direct Chemical and Biochemical Transformations of Starch. Carbohydr. Polym. 2018, 181, 460-476. [CrossRef]

11. Zhu, F. Structures, Properties, Modifications, and Uses of Oat Starch. Food Chem. 2017, 229, 329-340. [CrossRef]

12. Dos Santos, D.M.; Ascheri, D.P.R.; Bukzem, A.L.; Morais, C.C.; Carvalho, C.W.P.; Ascheri, J.L.R. Physicochemical properties of starch from avocado seed (Persea Americana Mill). Bol. Cent. Pesqui. Process. Aliment. 2016, 34, 1-12. [CrossRef]

13. Maniglia, B.C.; Blácido, D.R. Isolation and Characterization of Starch from Babassu Mesocarp. Food Hydrocoll. 2016, 55, 47-55. [CrossRef]

14. Araújo, R.G.; Rodriguez-Jasso, R.M.; Ruiz, H.A.; Pintado, M.M.E.; Aguilar, C.N. Avocado by-Products: Nutritional and Functional Properties. Trends Food Sci. Technol. 2018, 80, 51-60. [CrossRef]

15. Chel-Guerrero, L.; Barbosa-Martín, E.; Martínez-Antonio, A.; González-Mondragón, E.; Betancur-Ancona, D. Some Physicochemical and Rheological Properties of Starch Isolated from Avocado Seeds. Int. J. Biol. Macromol. 2016, 86, 302-308. [CrossRef] [PubMed]

16. Liu, G.; Gu, Z.; Hong, Y.; Cheng, L.; Li, C. Structure, Functionality and Applications of Debranched Starch: A Review. Trends Food Sci. Technol. 2017, 63, 70-79. [CrossRef] 
17. Ovando-Martínez, M.; Whitney, K.; Reuhs, B.L.; Doehlert, D.C.; Simsek, S. Effect of Hydrothermal Treatment on Physicochemical and Digestibility Properties of Oat Starch. Food Res. Int. 2013, 52, 17-25. [CrossRef]

18. Lacerda, L.G.; Da Silva Carvalho Filho, M.A.; Bauab, T.; Demiate, I.M.; Colman, T.A.D.; Andrade, M.M.P.; Schnitzler, E. The Effects of Heat-Moisture Treatment on Avocado Starch Granules: Thermoanalytical and Structural Analysis. J. Therm. Anal. Calorim. 2015, 120, 387-393. [CrossRef]

19. Hsieh, C.; Liu, W.; Whaley, J.K.; Shi, Y. Structure, Properties, and Potential Applications of Waxy Tapioca Starches-A Review. Trends Food Sci. Technol. 2019, 83, 225-234. [CrossRef]

20. Builders, P.F.; Nnurum, A.; Mbah, C.C.; Attama, A.A.; Manek, R. The Physicochemical and Binder Properties of Starch from Persea Americana Miller (Lauraceae). Starch/Staerke 2010, 62, 309-320. [CrossRef]

21. Galanakis, C.M. Recovery of High Added-Value Components from Food Wastes: Conventional, Emerging Technologies and Commercialized Applications. Trends Food Sci. Technol. 2012, 26, 68-87. [CrossRef]

22. Lara-Flores, A.A.; Araujo, R.G.; Rodrigues, R.M.; Aguedo, M.; Aguilar, C.N.; Trajano, H.L.; Ruiz, H.A. Bioeconomy and Biorefinery: Valorization of Hemicellulose from Lignocellulosic Biomass and Potential Use of Avocado Residues as a Promising Resource of Bioproducts. In Waste to Wealth; Singhania, R.R., Agarwal, R.A., Kumar, R.P., Sukumaran, R.K., Eds.; Springer: Singapore, 2018; pp. 141-170.

23. Kala, H.K.; Mehta, R.; Sen, K.K.; Tandey, R.; Mandal, V. Critical Analysis of Research Trends and Issues in Microwave Assisted Extraction of Phenolics: Have We Really Done Enough. Trends Anal. Chem. 2016, 85, 140-152. [CrossRef]

24. Zhang, H.F.; Yang, X.H.; Wang, Y. Microwave Assisted Extraction of Secondary Metabolites from Plants: Current Status and Future Directions. Trends Food Sci. Technol. 2011, 22, 672-688. [CrossRef]

25. Chemat, F.; Cravotto, G. Microwave-Assisted Extraction for Bioactive Compounds; Theroy and Practise (Volume 4); Springer Science \& Business Media: Berlin/Heidelberg, Germany, 2013.

26. Silva, I.R.A.; Magnani, M.; de Albuquerque, F.S.M.; Batista, K.S.; de Souza Aquino, J.; Queiroga-Neto, V. Characterization of the Chemical and Structural Properties of Native and Acetylated Starches from Avocado (Persea Americana Mill.) Seeds. Int. J. Food Prop. 2017, 20, S279-S289. [CrossRef]

27. AOAC. Official Methods of Analysis, 15th ed.; Methods 932.06, 925.09, 923.03, 991.43; Association of Official Analytical Chemists: Gaithesburg, MD, USA, 1995.

28. Aguilar-Reynosa, A.; Romaní, A.; Rodríguez-Jasso, R.M.; Aguilar, C.N.; Garrote, G.; Ruiz, H.A. Comparison of Microwave and Conduction-Convection Heating Autohydrolysis Pretreatment for Bioethanol Production. Bioresour. Technol. 2017, 243, 273-283. [CrossRef] [PubMed]

29. Ruiz, H.A.; Cerqueira, M.A.; Silva, H.D.; Rodríguez-Jasso, R.M.; Vicente, A.A.; Teixeira, J.A. Biorefinery Valorization of Autohydrolysis Wheat Straw Hemicellulose to Be Applied in a Polymer-Blend Film. Carbohydr. Polym. 2013, 92, 2154-2162. [CrossRef] [PubMed]

30. Abaide, E.R.; Zabot, G.L.; Tres, M.V.; Martins, R.F.; Fagundez, J.L.; Nunes, L.F.; Druzian, S.; Soares, J.F.; Dal Prá, V.; Silva, J.R.F.; et al. Yield, Composition, and Antioxidant Activity of Avocado Pulp Oil Extracted by Pressurized Fluids. Food Bioprod. Process. 2017, 102, 289-298. [CrossRef]

31. De la Torre-Gutiérrez, L.; Chel-Guerrero, L.A.; Betancur-Ancona, D. Functional Properties of Square Banana (Musa Balbisiana) Starch. Food Chem. 2008, 106, 1138-1144. [CrossRef]

32. Zortéa-Guidolin, M.E.B.; Demiate, I.M.; de Godoy, R.C.B.; de Paula Scheer, A.; Grewell, D.; Jane, J.-L. Structural and Functional Characterization of Starches from Brazilian Pine Seeds (Araucaria Angustifolia). Food Hydrocoll. 2017, 63, 19-26. [CrossRef]

33. Chen, J.; Liang, Y.; Li, X.; Chen, L.; Xie, F. Supramolecular Structure of Jackfruit Seed Starch and Its Relationship with Digestibility and Physicochemical Properties. Carbohydr. Polym. 2016, 150, 269-277. [CrossRef]

34. Song, Y.; Jane, J. Characterization of Barley Starches of Waxy, Normal, and High Amylose Varieties. Carbohydr. Polym. 2000, 41,365-377. [CrossRef]

35. Buksa, K. Extraction and Characterization of Rye Grain Starch and Its Susceptibility to Resistant Starch Formation. Carbohydr. Polym. 2018, 194, 184-192. [CrossRef]

36. Aguilar-González, M.Á.; Gorokhovsky, A.V.; Aguilar-Elguezabal, A. Removal of Lead and Nickel from Aqueous Solutions by $\mathrm{SiO}_{2}$ Doped Potassium Titanate. Mater. Sci. Eng. B 2010, 174, 105-113. [CrossRef]

37. Pozo, C.; Rodríguez-Llamazares, S.; Bouza, R.; Barral, L.; Castaño, J.; Müller, N.; Restrepo, I. Study of the Structural Order of Native Starch Granules Using Combined FTIR and XRD Analysis. J. Polym. Res. 2018, 25, 1-8. [CrossRef] 
38. Luchese, C.; Garrido, T.; Corralo Spada, J.; Cristina Tessaro, I.; de la Caba, K. Development and Characterization of Cassava Starch Films Incorporated with Blueberry Pomace. Int. J. Biol. Macromol. 2018, 106, 834-839. [CrossRef] [PubMed]

39. Zhang, L.; Xie, W.; Zhao, X.; Liu, Y.; Gao, W. Study on the Morphology, Crystalline Structure and Thermal Properties of Yellow Ginger Starch Acetates with Different Degrees of Substitution. Thermochim. Acta J. 2009, 495, 57-62. [CrossRef]

40. Nie, H.; Li, C.; Liu, P.; Lei, C.; Li, J. Retrogradation, Gel Texture Properties, Intrinsic Viscosity and Degradation Mechanism of Potato Starch Paste under Ultrasonic Irradiation. Food Hydrocoll. 2017, 95, 590-600. [CrossRef]

41. Kolling, W.M. Physical, Thermal and Sorption Profile of Starch Obtained from Tacca Leontopetaloides. Starch/Starke 2005, 57, 55-61.

42. Fan, D.; Ma, S.; Wang, L.; Zhao, J.; Zhang, H.; Chen, W. Effect of Microwave Heating on Optical and Thermal Properties of Rice Starch. Starch/Starke 2012, 2012, 1-5. [CrossRef]

43. Xie, Y.; Yan, M.; Yuan, S.; Sun, S.; Huo, Q. Effect of Microwave Treatment on the Physicochemical Properties of Potato Starch Granules. Chem. Cent. J. 2013, 7, 1-7. [CrossRef]

44. Do Prado Cordoba, L.; Ribeiro, L.S.; Rosa, L.S.; Lacerda, L.G.; Schnitzler, E. Effect of Enzymatic Treatments on Thermal, Rheological and Structural Properties of Pinhão Starch. Thermochim. Acta 2016, 642, 45-51. [CrossRef]

45. Beninca, C.; Colman, D.; Gustavo, L.; Beninca, C.; Andre, T.; Aure, M.; Bannach, G.; Schnitzler, E. Thermal, Rheological, and Structural Behaviors of Natural and Modified Cassava Starch Granules, with Sodium Hypochlorite Solutions. J. Therm. Anal. Calorim. 2013, 111, 2217-2222. [CrossRef]

46. Malumba, P.; Doran, L.; Zanmenou, W.; Odjo, S.; Katanga, J.; Blecker, C.; Béra, F. Morphological, Structural and Functional Properties of Starch Granules Extracted from the Tubers and Seeds of Sphenostylis Stenocarpa. Carbohydr. Polym. 2017, 178, 286-294. [CrossRef]

47. Wijaya, C.; Diem, Q.; Hsu, Y.; Permatasari, S.; Nyoo, J.; Laysandra, L.; Edi, F.; Ismadji, S. Heliyon Isolation and Characterization of Starch from Limnophila Aromatica. Heliyon 2019, 5, 1-7. [CrossRef]

48. Luo, F.; Huang, Q.; Fu, X.; Zhang, L.; Yu, S. Preparation and Characterisation of Crosslinked Waxy Potato Starch. Food Chem. 2009, 115, 563-568. [CrossRef]

49. Warren, FJ.; Gidley, M.J.; Flanagan, B.M. Infrared Spectroscopy as a Tool to Characterise Starch Ordered StructureA Joint FTIR-ATR, NMR, XRD and DSC Study. Carbohydr. Polym. 2016, 139, 35-42. [CrossRef] [PubMed]

50. Karim, A.A.; Norziah, M.H.; Seow, C.C. Methods for the Study of Starch Retrogradation. Food Chem. 2000, 71,9-36. [CrossRef]

51. Ruiz, A.; Rodríguez, R.M.; Fernandes, B.D.; Vicente, A.; Teixeira, A. Hydrothermal Processing, as an Alternative for Upgrading Agriculture Residues and Marine Biomass according to the Biorefinery Concept: A Review. Renew. Sustain. Energy Rev. 2013, 21, 35-51. [CrossRef]

52. Rostro, M.; Sánchez-González, M.; Rivas, S.; Moure, A.; Domínguez, H.; Carlos, J. Non-Isothermal Autohydrolysis of Nixtamalized Maize Pericarp: Production of Nutraceutical Extracts. LWT Food Sci. Technol. 2014, 58, 550-556. [CrossRef]

53. Rigual, V.; Santos, T.M.; Domínguez, J.C.; Alonso, M.V.; Oliet, M.; Rodriguez, F. Combining Autohydrolysis and Ionic Liquid Microwave Treatment to Enhance Enzymatic Hydrolysis of Eucalyptus Globulus Wood. Bioresour. Technol. 2018, 251, 197-203. [CrossRef]

54. Santos, T.M.; Alonso, M.V.; Oliet, M.; Domínguez, J.C.; Rigual, V.; Rodriguez, F. Effect of Autohydrolysis on Pinus Radiata Wood for Hemicellulose Extraction. Carbohydr. Polym. 2018, 194, 285-293. [CrossRef]

(C) 2020 by the authors. Licensee MDPI, Basel, Switzerland. This article is an open access article distributed under the terms and conditions of the Creative Commons Attribution (CC BY) license (http://creativecommons.org/licenses/by/4.0/). 